\title{
SEISMOTECTONICS OF ZIMBABWE
}

\author{
J.H. Dumisani \\ Applied Physics Department, Faculty of Sciences \\ National University of Science and Technology, \\ P. O. Box AC 939 Ascot, Bulawayo, Zimbabwe \\ E-mail: dumisanij@hotmail.com
}

\begin{abstract}
The seismotectonics of Zimbabwe is presented in this paper. Data used in the study are from instrumental records for the period 1910-1991 sourced from available seismological bulletins. Earthquake magnitudes are unified to surface-wave magnitude (Ms), facilitating easy evaluation of seismicity of the region. Seismicity is confined to regions with broad scale lineaments that trend in a north-easterly direction. Seismic hazard potential for Zimbabwe may be inferred from the total magnitude representing the seismic wave energy. Fault plane solutions and energy release during the period of study show that high seismic hazard potential lies along the Deka fault zone midZambezi basin to the north and northwest of Zimbabwe, in the Save-Limpopo mobile belt to the south of Zimbabwe and along the Zimbabwe eastern highlands, bordering Mozambique.
\end{abstract}

Key words: seismicity, seismic energy, hazard potential, fault lineaments.

\section{INTRODUCTION}

The demand in modern seismology today is for accurate earthquake data that are both homogeneous and complete. This is necessary to be able to map out hidden tectonic features and assess seismic hazard. The seismotectonics of Zimbabwe is presented in this paper with this requirement in mind. Although the period 1910-1991 is being considered for the results in this paper, it is worth emphasizing that the period 1910-1950 is characterised by a lack of data. Two events, Ms magnitude $6(\mathrm{mb} \approx 5.9)$, occurred, one in 1910 and the other in 1940. These events are significant for a region of low seismicity like the one in this study. They were instrumentally recorded, and contribute in seismic hazard calculations for the region. Although more data became available in the early 1950's, only events of moderate magnitude (i. e. magnitude $>5$ ) appear in the records. Work in the region has focused on induced seismicity at Lake Kariba (Gough \& Gough 1970, Gupta et al 1972a, 1972b, Gupta \& Rastogi 1976, Gough 1978), magnitude determination (Henderson 1974, Chow et al 1980) and fault plane solutions (Maasha \& Molnar 1972, Shudofsky 1985, Hlatywayo 1995) to name just a few. The homogenized earthquake data set developed for this study will in future studies be used in seismic hazard calculations in the region. This paper therefore provides primary data on Zimbabwe that is required by both geophysicists and the construction engineers.
Zimbabwe lies over the southern tip of the east Africa rift system (Fig. 1). The south-east (Save-Limpopo basin) and the north-west (the Deka fault zone mid-Zambezi basin) areas of the region are covered by Karroo sediments that comprise $15 \%$ of Zimbabwe. These sediments wedge out towards the centre of Zimbabwe. The rest of Zimbabwe is part of a continental shield with little seismicity. Considerable seismic activity occurs along the Zimbabwe south-eastern border with Mozambique and the Deka fault zone mid-Zambezi basin. Activity in central western Mozambique is of pure tectonic origin while that along the Zambezi basin is contaminated with reservoir induced seismicity (related to the Kariba dam).

\section{GENERAL TECTONICS}

On the African continent, the east Africa rift system is the most pronounced tectonic feature. The southern extent of this system is well defined only as far south as Lake Malawi, i.e. approximately $15^{\circ} \mathrm{S}$ latitude. Beyond this point, there exists very little in the form of surface features to suggest rifting. In this area, the rift system ceases to be confined to clearly defined narrow belts and rifting may be considered only on account of shallow seismic activity. Sykes (1970) proposed that the pattern of failure is more complex in continental areas than in oceanic areas, perhaps because continents are older and contain many zones of weakness; and, south of the equator, the initial break-up of Africa is in 
an early stage. This initial pattern of break-up is normally complex and multi-branched. Maasha and Molnar (1972) observed that activity in southern Africa remained high when compared to other continental regions in spite of the absence of active rifting. Lineaments in the Deka fault zone mid-Zambezi basin to the north-west of Zimbabwe trend in a north-easterly direction extending further north into the Luangwa rift in eastern Zambia (Fig. 1). The surface is covered with thick Karroo sediments of Mesozoic and Palaeozoic ages. The karroo sediments of the mid-Zambezi basin extend south-west-wards through the Deka fault zone into Botswana. The general geology is white and red sandstones overlain by basaltic lavas approximately $700 \mathrm{~m}$ thick (Maufe 1924, Vail 1967, Reeves \& Hutchins 1975). Close to the north-western edges of the Karroo sediments lies the Deka fault marking a line of fault throwing down to the north-west.

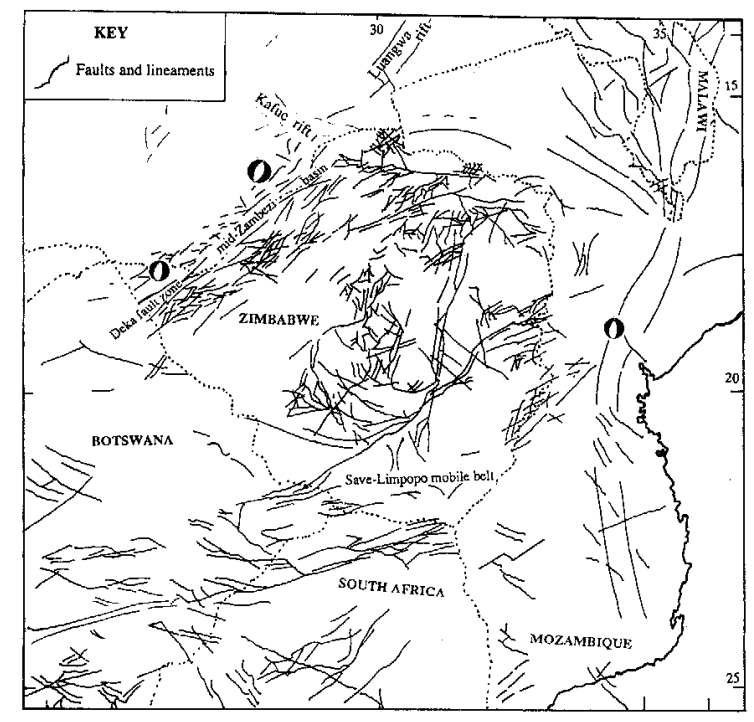

Figure 1. Map of central southern Africa showing the broad-scale lineaments and faults. The three focal mechanisms shown give the general fault solutions that have been obtained in the region and their tensile axis.

Using the seismicity of southern Africa and areas to the north, i.e. extending north-wards into the rift system, several authors have suggested incipient rifting to extend this far south along longitude $26^{\circ} \mathrm{E}$ (Fairhead \& Girdler 1969a, b, Fairhead \& Henderson 1977). There are, however, no notable major fault lineaments trending north-wards along $26^{\circ} \mathrm{E}$ from either Zimbabwe or Botswana to support rifting along this line. A map of the post-Karroo rifting, shows the trend of lineaments from Botswana running north-easterly through the Deka fault zone and the midZambezi basin into the Luangwa rift (Fig. 1). As follows from the present study, there is a belt of epicentre concentrations lying along this zone. Reeves (1972), reports the Kalahari seismic axis is an aligned extension of the Deka fault zone mid-Zambezi basin to the Luangwa karroofilled rift. Migratory rift-faulting is believed to have been the controlling force of the karroo belt. McKenzie et al. (1970) have treated the east Africa rift system as a plate boundary. No evidence has been put forward to suggest that the east Africa rift connects with the mid-Indian Ocean Ridge to the south. All indications from the study of the seismicity of southern Africa point towards the southern tip of the western arm of the east Africa rift, terminating on the continent. Accretion of new crustal material over the areas now under discussion does not exist and the lithosphere has been found to be still unbroken (Scholz et al. 1976). This area, therefore, represents some early mode of break-up that has not started, yet it is visible in the guise of a sub-plate boundary. Scholz et al. (1976), found concentrations of epicentres of earthquakes trending along a north-easterly direction from Botswana into the Deka fault zone mid-Zambezi basin - Luangwa rift, suggesting a branch of the east Africa rift system starting off from just north of Malawi. The area studied falls in the region of the southern tip of the East Africa rift system. The southeastern Zimbabwe area along the border with Mozambique, forms the western flanks of the rift extension through Lake Malawi. Along the Zimbabwe eastern border, the area comprises highly folded and sheared quartzites separated from neighbouring formations by numerous faults. The main lineaments trend in an east-north-east direction ( Fig. $1)$.

\section{DATA}

The study area is shown in Fig. 1. Included in this area besides all of Zimbabwe, are parts of Zambia, Mozambique, South Africa and Botswana. The choice of the area made it possible to study the seismicity of Zimbabwe and its surroundings. The main areas of activity in the region are included. All data found in available catalogues and seismological bulletins published by different reporting agencies are used. Besides the Zimbabwe seismological bulletins data sources included the National Earthquake Information Service, USA (NEIS) catalogue (1904 - 1987) and the British Geological Survey (BGS) Sub-Saharan African Earthquake Catalogue (Musson 1994).

There are 3980 events in the data set. All events except a few (31 events) were recorded by the Zimbabwe 
seismological network. The Department of Meteorology of the Zimbabwe Government (formerly, Rhodesia Meteorological Services) operated six stations in Zimbabwe, Zambia and Malawi during most of the last 30 years of the period for this study. Monitoring of earthquakes in Zimbabwe arose out of an interest to record the effects of the Lake Kariba reservoir on seismic activity in the area. Although dam construction began early in the 1950 's, seismograph stations were not deployed to monitor seismic activity until 1959, the year that the dam wall was impounded. A permanent network of six stations was put in place by 1966 . It therefore means that going by the network detection capability, data completeness may only be considered for the period after 1966. From 1963 Zimbabwe operated a six component World Wide Seismograph Station Network (WWSSN) seismograph at Bulawayo (BUL). In 1980, when Zimbabwe ceased operating the Broken Hill seismograph station in Zambia, Zambia began building up a network of six stations that became fully operational by 1985. Zimbabwe seismographs recorded on photographic paper. All records were sent to BUL for both analysis and archiving. BUL also received seismological bulletins from the South Africa and Mozambique seismograph network. Data from these bulletins were used in earthquake location to complement earthquake phase data readings from the Zimbabwe seismograms. The data were useful in the location of events to the south along the Zimbabwe-South Africa border and in Mozambique. From 1985 onwards, seismological bulletins from Lusaka, Zambia became available. Earthquake phase data from these bulletins were incorporated into the data to achieve more accurate epicentre locations. All events detected by the Zimbabwe seismograph network were manually located. With an increase in the number of seismograph stations in the region towards the end of the period of this study, event detection capability was enhanced and epicentre location improved. BUL manual locations are shown in the International Seismological Centre (ISC) bulletins along side the ISC hypocentre locations i.e. where these were calculated by the ISC. These manual locations lie within \pm $0.2^{\circ}$ (in latitude and longitude) of the ISC locations. There are 242 events with magnitude $\geq 4.0$ in the data set. These magnitudes are completely recorded for the period 1966 1991. For these events, hypocentral parameters were recalculated using the program HYPOINVERSE (Klein 1978) on computer. The results obtained were not different from the ISC given locations: the majority of the manual locations still lay within $\pm 0.2^{\circ}$ of the computer locations. The close resemblance of these results to the ISC values is not surprising since the ISC determined their hypocentres (e.g. where they are given ) from phase data supplied by the reporting agencies within the region. The same phase data were used in this study for the event relocations. This exercise however, served to show the nature of the BUL manual epicentre location deviations from computer aided locations.

\section{UNIFICATIONOFMAGNITUDES}

There are several different magnitude scales in use today and magnitude determination continues to be a subject of discussion. Even with magnitudes that are determined from the same scale, there are significant and consistent differences determined by different seismological centres. The ISC, in their seismological bulletins, give the final record of earthquake parameters including magnitude. Some events in the present data set are reported in the ISC bulletins with no magnitudes and more than $75 \%$ of the events whose magnitudes are given in these bulletins show BUL reported magnitudes. It therefore seems quite reasonable to work with a data set based on BUL magnitudes. BUL reports magnitudes of $\mathrm{mb} L g$ type determined from the relation

$\mathrm{mb} \quad=\log [A / T]+B[\Delta]$

where $A$ is the ground motion amplitude of the $L g$ phase in $\mu \mathrm{m}, T$ is the period in seconds and the $B[\Delta]$ term accounts for the effects of epicentral distance and station correction. The relation assumes shallow foci events (i.e. 0 to $10 \mathrm{~km}$ depth). Details on this relation are found in Henderson (1974) and Chow et al. (1980). Chow et al. (1980) found mb (BUL) magnitudes on average, to be 0.16 units higher than ISC values. All data for the period 1963-1991 are based on this magnitude. Magnitudes for all events were homogenised to a surface wave magnitude type, Ms using the theoretical scaling relation of Geller (1976)

$\mathrm{mb}=0.33 \mathrm{Ms}+3.91$

This relation was derived for magnitudes $4.9<\mathrm{Ms}<$ 6.27. However, an extrapolation to lower magnitudes was done on the data in the full knowledge that some errors may be introduced into the data magnitudes in so doing. The results are taken for $\mathrm{mb}$ (BUL) magnitudes. The errors introduced in the data set certainly weigh heavily upon its homogeneity. It is also noted that for seismic hazard purposes, magnitudes less than 4.0 contribute insignificantly. For purposes of this study, the data will be assumed to be homogeneous in magnitude, Ms. 


\section{SPATIAL DISTRIBUTION OFEARTHQUAKES}

All 3980 events in the data set are assumed to have shallow foci, (0 to $10 \mathrm{~km}$ depth). The epicentre location map in Fig. 2 gives the seismicity of the area in this study for the 82year period from 1910 - 1991 for the available data. Two areas of high seismic activity are observed on the map: a) the area along eastern borders of Zimbabwe and Mozambique, trending north-east-wards into central Mozambique b) the Deka fault zone mid-Zambezi basin to the north-west, trending in a north-east direction into the Luangwa rift in eastern Zambia. The Deka fault zone midZambezi basin is further subdivided into two areas, i.e. the Deka fault zone and the mid-Zambezi basin. Most of the mid-Zambezi basin lies under the waters of the Lake Kariba. The two areas are shown in Fig. 2. Outside these two areas, epicentres are scattered and sparsely distributed. One other area deserving mention is southern Zimbabwe (centred on $21^{\circ} \mathrm{S}, 30^{\circ} \mathrm{E}$ ). This area is not as active as the Lake Kariba area in the mid-Zambezi basin. An event of magnitude Ms $=6$ occurred in southern Zimbabwe in 1940. This event occurred on the boundary of the Zimbabwe shield and the Save-Limpopo mobile belt. Since then, few small magnitude events have occurred in the vicinity of its epicentre.

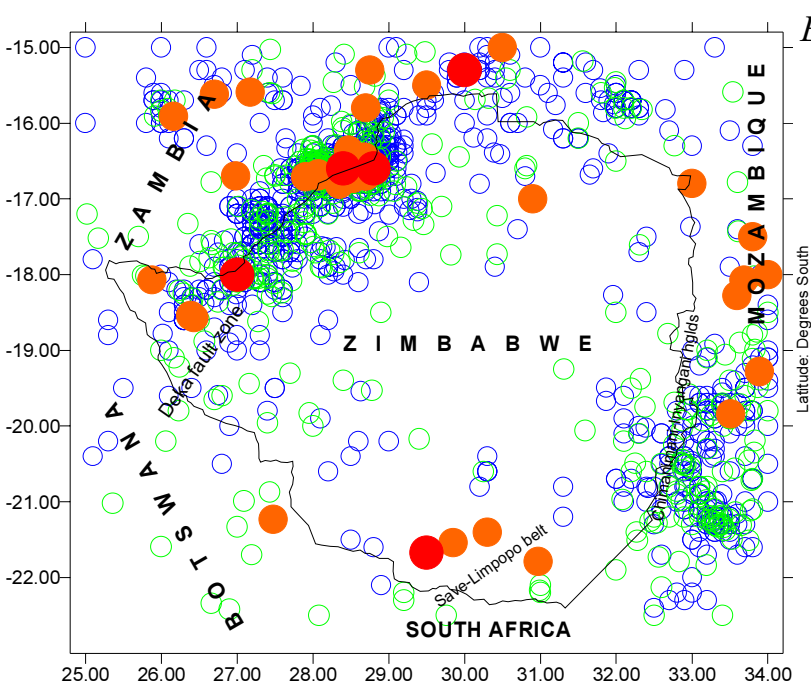

Figure 2 Spatial presentation of the seismicity of Zimbabwe for the period 1900 - 1994. Red solid circles are earthquakes of surface magnitude $M_{s} \geq 6.0$; orange solid circles are for magnitudes $5.0<$ $M s>5.9$; green open circles for $4.0 \leq M s \leq 4.9$ and the blue open circles for $M_{s}<3.9$.

\section{ENERGYMAP}

Earthquake magnitude allows us to make a classification of earthquakes based on seismic energy release. Båth (1979) discusses some of the simple relations giving logarithm of energy as a linear function of magnitude. These formulae use either local, surface-wave or bodywave magnitudes. The seismic energy relation (Båth 1979)

$$
\log _{10} E=12.24+1.44 M
$$

employing surface-wave magnitude is used in this study. Earthquakes of all magnitudes are incorporated in the energy release calculation. Seismic energy, E (in ergs), is calculated for each earthquake using the above formula. In this study, energy is mapped using the " moving-block method' (Båth 1980, 1982a, b). A moving block of area $1^{\circ} \mathrm{x}$ $1^{\circ}$ is successively shifted by $0.5^{\circ}$, partly in latitude and partly in longitude. Energy is calculated using equation [2]. Cumulative energy, , in each block is calculated by summing the seismic energy, of all earthquakes within the block for all magnitudes during the period 1910 - 1991, so that

$$
E_{T}=\sum E_{i}
$$

The total energy in each block, , is then converted to an equivalent total hypothetical magnitude, $M_{T}$, using

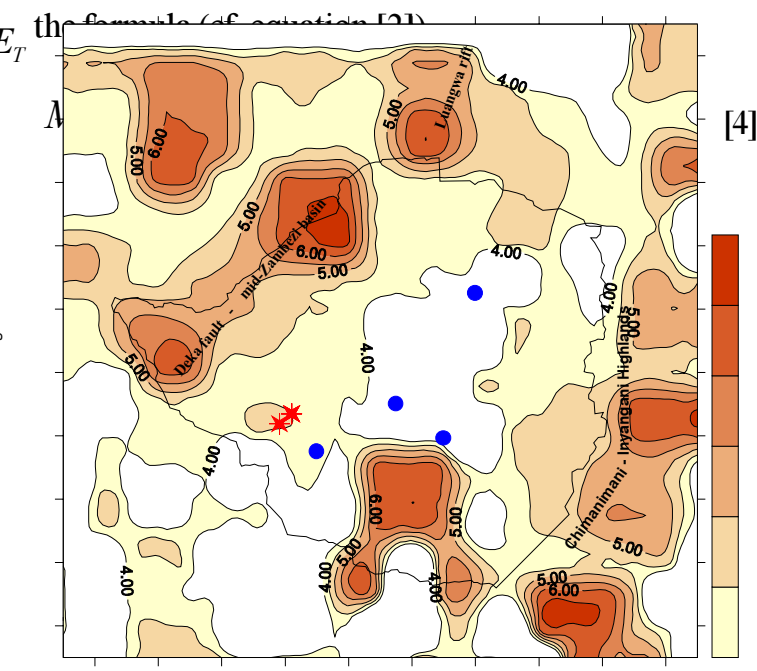

Figure 3. Seismicity of Zimbabwe rendered as Total magnitude and contoured from values obtained from calculations at $0.2^{\circ}$ grid points. represents energy released at the grid points. The pattern obtained shows areas of high energy release similar to those of high seismic activity. 
It was borne in mind that energy is a discontinuous point function which has high values at particular points (epicentres) and zeroes at points in the neighbourhood. Isolines of 0.5 magnitude units apart are traced in the energy mapping. The method used in energy calculation and the tracing of magnitude-isolines in the energy mapping smoothes out the discontinuity properties. Areas of high seismicity, closely resembling the epicentre mapping of Fig. 2 are identified in the energy map of Fig. 3. Areas of high energy release as revealed in Fig. 3, do not necessarily portray areas where there have been large numbers of earthquakes but instead indicate areas where earthquakes of larger magnitude have occurred. Two areas of high energy release are observed in Fig. 3: the area to the northwest of Zimbabwe, trending southwest - northeast-wards along the Deka fault zone mid-Zambezi basin into the Luangwa rift in eastern Zambia and eastern Zimbabwe bordering with Mozambique and extending into central Mozambique. A total earthquake magnitude in excess of 6 is calculated for both areas. One area of interest that is outside the two main areas discussed above, lying in southern Zimbabwe (Fig. 3) shows a total magnitude in excess of 6 . This energy is a result of the 1940 magnitude 6 event that occurred in there. Being the only large event reported in the area, it stands out as a characteristic event with an unknown recurrence period. With small magnitude events occurring in the same area since 1940, the area may be considered to possess a potential to yield an event of similar magnitude in the future.

For engineering purposes and earthquake prediction, an estimate of the likely maximum magnitude in a certain locality is an important parameter. Results of Fig. 3 may be converted into maximum possible magnitude expected within each block and used to estimate the maximum intensity and acceleration within the block, i.e. assuming the data are representative of long-term seismicity.

\section{DISCUSSIONAND CONCLUSIONS}

The largest earthquake of magnitude 6.4 entering the present data set occurred in the mid-Zambezi basin on September 23, 1963. From energy calculations, a total magnitude of 6.6 is obtained in the mid-Zambezi basin and to the southeast of Zimbabwe in Mozambique. The area studied shows relatively moderate seismicity in both spatial distribution of earthquakes and energy release. Activity in the mid-Zambezi basin is attributed mainly to reservoir induced seismicity (Gough \& Gough 1970; Gough 1978). This area shows evidences of volcanism in its past history and is characterised by the presence of rocks that are highly porous. Gupta et al. (1972 a, b) and others have proposed pore pressure to play a major role in event triggering in the mid-Zambezi basin. The seismic history of the mid-Zambezi basin before the existence of the Lake Kariba will remain obscure. There was no earthquake monitoring in the area before the reservoir was constructed. However, a few events are known to have occurred in the area before the dam wall was sealed in December 1958. Ambraseys and Adams (1991) report one such event of surface-wave magnitude 6 occurring in the area on May 28, 1910. Such events support the existence of natural tectonics and seismic activity in the mid-Zambezi basin before the Lake Kariba dam was constructed. Scholz et al. (1976) noted events located by Gough and Gough (1970), fifty kilometres to the north of the Lake Kariba dam as evidence of some natural tectonic activity.

Hlatywayo (1995) reports faulting in this area to be predominantly normal with tensile stresses directed in a northwest-southeast direction. Maasha and Molnar (1972), Scholz et al (1976), Shudofsky (1985) and others have concluded in their works that the southern African region is under a northwest-southeast extension normal to the direction of the main lineaments. Maasha and Molnar (1972) report the directions of the principal stresses in the region to be similar to those that existed in the east Africa rift from the Miocene period.

Fault plane solutions of three events in the areas are shown in Fig 1. These solutions were determined from P-wave onset polarities (Hlatywayo 1995). The same mechanism, i.e. normal faulting, is obtained in all solutions. If the respective fault planes are selected from considerations of main fault trends, then all three solutions will give a similar strike direction. These results indicate that the three areas are under similar stresses and tectonics. The Deka fault zone mid-Zambezi basin tectonic setting is therefore similar to that of the Mozambique area that forms the southern limits of the east Africa rift passing through Lake Malawi. This similarity may explain the high activity in the midZambezi basin that is observed several decades after the dam at Kariba impounded. Admittedly, the reservoir at Kariba in the mid-Zambezi basin continues to trigger some events within the area as a result of the presence of pore pressure differentials but this may not receive all the credit for the activity in the mid-Zambezi basin during the period 1966 - 1991. The general trend of induced seismic activity around reservoirs is to decrease gradually with time after the reservoir has filled. In the mid-Zambezi basin, activity has remained relatively high. The persistent high activity must be due to natural tectonics.

Both the Deka fault zone mid-Zambezi basin and the Zimbabwe eastern highlands areas show high earthquake activity in terms of numbers, high energy release rendered 
as total magnitude and similar earthquake mechanisms with maximum horizontal stress axes in the north-west southeast direction. If activity in the Zimbabwe-Mozambique border area is in response to the tectonics of the extension of the east Africa rift, then, inferring from the similarities with the Deka fault zone-mid Zambezi basin, it may be concluded that a branch of the east Africa rift through the Luangwa rift (Fig. 1) indeed extends far south as the Deka fault zone. The two areas of major earthquake activity found in this study are under similar tectonic stresses and respond to these forces in the same manner. Earthquake distribution in the whole area studied reflects the response of the earth's crust to the stresses that appear to extend the zone of rifting south-wards.

Seismic hazard potential of Zimbabwe may be inferred from Fig. 3 that gives seismic energy released during the period of study as total magnitude. From the total magnitude, it is possible to deduce the maximum seismic intensity as well as the maximum peak ground PGA acceleration possible in Zimbabwe. Areas of high energy release will correspond to areas of high peak horizontal ground acceleration or high earthquake intensity. Therefore, Fig. 3 is indeed a seismic hazard map of Zimbabwe valid for data available at the time of study. Two earthquakes recently occurred just to the northwest of Bulawayo City; one, on $19^{\mathrm{TH}}$ February 1999 (Time: 1202 UTC, Co-ordinates: $28.10^{\circ} \mathrm{E}, 19.65^{\circ} \mathrm{S}$ ) and the second on $29^{\mathrm{TH}}$ March 1999 (Time: 0125 UTC; Coordinates: $27.91^{\circ} \mathrm{E}, 19.81^{\circ} \mathrm{S}$ ). The events registered Coda magnitudes of 3.7 and 3.9 respectively. Epicentres are shown as stars in Fig. 3 and marked [I] and [II] respectively. The two events serve to confirm the seismic potential inferred in the results of Fig.3. They were widely felt in nearly all the surburbs of Bulawayo City with an intensity of III on the MM Scale. Bulawayo City has close to a million inhabitants. The hazard map of Fig. 3 derived from total magnitude shows Bulawayo City lying in an area of possible maximum magnitude, $\mathrm{MS}=4.0$. This map is therefore of importance to both the engineer and the planning officer in Zimbabwe. It should be pointed out though, that data are only representative of an 80-year period. Earthquakes are known to possess return periods in excess of a hundred years. The results of Fig. 3 should therefore be strictly treated as showing seismic hazard estimates or hazard potential in Zimbabwe.

\section{ACKNOWLEDGEMENTS}

This study was done with the assistance of staff at Goetz Observatory, Bulawayo, Zimbabwe, to whom I am grateful. In particular, Ezekiel Jonathan gave valuable suggestions to the contents of the manuscript for which I am truly thankful. I am also deeply indebted and owe my thanks to
Lovemore Masawi and Rodgers Munyira, all of GoetZ Observatory, for assistance in the collection of phase data that were required in hypocentre relocations of 242 events in the data set from old seismograms and bulletins.

\section{REFERENCES}

Ambraseys N. N and Adams R. D, 1991. Reappraisal of major African earthquakes, south of 20 N, 19001930, Natural Hazards 4,389 - 419.

Båth M., 1979. Introduction to Seismology, Birkhäuser, 2nd edition, 105-168.

Båth M., 1980. Earthquake energy and frequency in the Tanzania region, Boll. Geof. Teorica ed Applicata, 22, 171-186.

Båth M., 1982a. Seismic energy mapping applied to Turkey, Tectonophysics, 82, 69-87.

Båth M., 1982b. Seismic energy mapping applied to Sweden, Tectonophysics, 81, 85-98.

Chow C. A. R., J. D. Fairhead, N. B. Henderson and P. D. Marshall, 1980. Magnitude and Q determinations in Southern Africa using Lg wave amplitudes, Geophys. J. R. astr. Soc. 63, 735-745

Fairhead D. J. and R. W. Girdler, 1969a. How far does the Rift System extend through Africa? Nature, 221, 1018 -1020 .

Fairhead D. J. and R. W. Girdler, 1969b. Evolution of rifting in Africa. Nature, 224, 1178 - 1182.

Fairhead D. J and N. B. Henderson, 1977. The seismicity of Southern Africa and incipient rifting, Tectonophysics, 41, T19-T26.

Geller J.R., 1976. Scaling relations for earthquake source parameters and magnitude, Bull. Seism. Soc. Am., 66, $1501-1523$.

Gough D.I. and W. I. Gough, 1970. Load - induced earthquakes at Lake Kariba -II, Geophys. J.R. astr. Soc., 21, 79-101.

Gough D.I., 1978. Induced Seismicity: The Assessment and Mitigation of Earthquakes, Risk- UNESCO 1978, 91117.

Gupta K. H., B. K. Rastogi and H. Narain, 1972a. Some discriminating characteristics of earthquakes near the Kariba, Kremasta and Koyna artificial lakes, Bull. Seismol. Soc. Am., 62,493 -507.

Gupta. H.K., B. K. Rastogi and H. Narain, 1972b. Common features of the Reservoir- associated seismic activities, Bull. Seismol. Soc. Am., 62, 481 - 492.

Gupta K. H. and B. K. Rastogi, 1976. Dams and Earthquakes, Elsevier, Amsterdam, 60 - 68.

Henderson B. N., 1974. Earthquake magnitude determination based on short period crustal waves, Rhodesia Meteorological Service, Meteorological Notes, Series 4, No. 42. 
Hlatywayo J. D., (1995). Fault-plane solutions of the Deka fault zone and mid-Zambezi basin, Geophys J. Int., 120, $567-576$.

Klein, W. R., 1978. Hypoinverse location program. HYPOINVERSE, part 1, Users guide; O $\quad$ e $n$ file report 78 - 694, U. S. Geol. Survey, Menlo Park, C. A.

Maasha N. and P. Molnar, 1972. Earthquake fault parameters and tectonics in Africa, J. Geophys. Res., 77, 5731 5742 .

Maufe B. H., 1924. An outline of the geology of Southern Rhodesia, S. Rhod. Geol Surv., Short Report, No 17.

McKenzie P. D., D. Davies and P. Molnar, 1970. Plate tectonics of the Red Sea and East Africa, Nature, 226,243 .

Musson W. M. R., 1994. The BGS Sub-Saharan African Earthquake Catalogue, British Geol Techn. Report, $\mathrm{WL} / 94 / 28,1-59$.

Reeves V. C., 1972. Rifting in the Kalahari ? Nature, 237, 95 $-96$.

Reeves V. C. and D. G. Hutchins, 1975. Crustal structures in central southern Africa. Nature, 254, 408 - 409.

Scholz H. C., T. A. Kocynski and D. G. Hutchins D. G., 1976. Evidence for incipient rifting in Southern Africa, Geophys. J.R. astr. Soc., 44, 135 - 144.

Shudofsky G. N., 1985. Source mechanisms and focal depths of East African earthquakes using Rayleigh-wave inversion and body-wave modelling, Geophys. J.R. astr. Soc., 83, 563 - 614.

Sykes R. L., 1970. Seismicity of the Indian Ocean and a possible nascent Island arc between Ceylon and Australia, J. Geophys. Res., 75, 5041 - 5055.

Vail R. J.., 1967. The Southern extension of the East Africa rift system and related igneous activity, Geol. Rands, 57, 601 - 614 . 